\title{
A PRELIMINARY INVESTIGATION OF A MODEL ON THE DECISION TO IMPLEMENT TELEWORKING IN THE JAPANESE BUSINESS ORGANIZATIONS
}

\author{
Abdul Azeez Kadar Hamsa ${ }^{1}$ \\ Kulliyyah of Architecture and Environmental Design \\ INTERNATIONAL ISLAMIC UNIVERSITY MALAYSIA \\ Masao Miura ${ }^{2}$ \\ SHIBAURA INSTITUTE OF TECHNOLOGY, JAPAN
}

\begin{abstract}
Teleworking, an alternative form of work arrangement, has gained very little significance in the present information era, as otherwise expected, in modern Japan. Existence of many factors would be directly responsible for the slow growth of teleworking in Japan. This paper highlights few significant factors responsible for the decision to accept teleworking as an alternate work arrangement as expressed by the managers of different business organizations in the Greater Tokyo Metropolitan Area (GTMA). These factors include but not limited to: organizational values, advantages of teleworking, performance evaluation, strategically measures and information technology requirements. A logistic regression model was developed to test the significance of these factors against the decision to implement teleworking. Finally, conclusions were also drawn.
\end{abstract}

Keywords: Teleworking, ICT, Model, Japanese Organizations

\section{INTRODUCTION}

The evolution of Information and Communication Technology (ICT) is accompanied by an abundance of organizational structural changes. To exemplify, telex was replaced by facsimile, electronic typewriters by high-speed computers, postal mails by electronic mail, and to some extent face-to-face

\footnotetext{
' Assistant Professor Dr. Abdul Azeez Kadar Hamsa can be contacted at azeez@iiu.edu.my

${ }^{2}$ Professor, Department of Architecture and Environmental System. He can be contacted at masao@sic.shibaura-it.ac.jp
} 
meetings by teleconferencing. These changes have eventually led to greater, quicker and relatively cheaper access of information. Moreover, it also grew attention in creating and performing many productive-oriented business activities. Telemedicine, teleshopping, teleconferencing, and teleworking or telecommuting are few common information technology- oriented activities, which might make use of one or more of information technology tools to accomplish work-related activities. Thus, information technology has been playing a greater role in facilitating activities located at a greater distant apart into reality. However, the scope of this paper is limited only to teleworking or telecommuting.

The concept of teleworking has generated a significant change with regard to the central workplace of the business organizations, which is no longer considered to be the only workplace for performing work-related activities (Christensen, 1990). It is accomplished mainly as a result of rapid progress in the information and communication technology field. The rapid growth of personal computer, fax, and mobile telephone in many countries are excellent examples toward this trend. A recent survey in Japan had indicated that nearly $100 \%$ of the companies surveyed were using desktop PCs followed by $90 \%$ using laptop/notebook PCs to carry out work related activities (EPA, 2000). On the other hand, the number of cellular mobile phone subscribers was estimated to be around 62.2 million in October 2000 (MPT, 2000) and has been increasing almost to 10 million subscribers annually. Nonetheless, the increasing growth of information and communication technology has seen very little impact on the penetration rate of teleworking in Japan. One of the main reasons is due to resistance by the management of the business organizations against the implementation of teleworking. The management uncertainty is also one of the biggest barriers to increased telecommuting in United States (Olson, 1989). The stagnant Japanese economy for a decade since early 1990's as some analysts quote as "The Lost 90's" (EPA, 2000) is considered the other possible cause for the slow progress of teleworking. A number of additional cultural norms were found to be other reasons, which inhibit the adoption of teleworking in Japan (Mokhtarian et. al., 1994). Indeed, the success of a teleworking arrangement is largely dependent on the manager (Hobbs et. al., 1998) and the teleworker and it is therefore important that both are enthusiastic about teleworking. It was also found that managers are expected to spend more time controlling teleworkers than conventional on-site workers (Haddon et. al., 1994) and often expressing concern about such lack of control (Gillespie et. al., 1995). Moreover, management practices and prejudices are still regarded as one of the greatest barriers to the development of teleworking (Suomi, 1997). One of the factors which inhibit take-up of teleworking in UK was resistance from managers in the 
organization who perhaps felt threatened or unable to give up control over remote staff (Huws et. al., 1996).

The inception of teleworking in Japan during late 1980's was very well received by the corporate management as the economy of the nation was in the steady increased path (Spinks, 1991). The booming economy in late 1980's has resulted in an increased of real estate cost especially at the center of major cities in Japan like Tokyo, Osaka and Nagoya. After the economy bubble burst in the early 1990's, many large and medium sized corporations, which were introduced teleworking, had started to considerably scale back the promotion of teleworking. On the other hand, the main cause for the relatively low growth of teleworking in Japan, however, is still largely need to be studied extensively despite improved innovation in the information and communication technology. This paper highlights some of the major issues, which are considered vital for the management to decide whether or not teleworking brings positive outlook for the corporations. As a result, the perceptions of the managers on each of the identified factors toward teleworking were analyzed. A binary logistic regression model was developed to assess the influence of each of the identified factors on the decision to introduce teleworking.

\section{OVERVIEW OF RESEARCH APPROACH}

The decision to implement teleworking in the Japanese organization, as perceived by the managers, was measured by using questionnaire survey. A pilot survey of the questionnaire was conducted to test the relevance of each of the questions in the questionnaire including survey method. A total number of 10 questionnaires were distributed to the managers of different business organizations in Tokyo area as part of the pilot survey. Few changes were made in the questionnaires before main survey was administered. The administration of main survey includes two sets of questionnaire, which were carried out in the Tokyo Metropolitan area at the end of the year 2000. It was primarily targeted to the business organizations, which have been practicing teleworking successfully (Group I) and the organizations, which are potential to consider but were not practicing teleworking (Group II) at the time of survey. The respondents of each of the two questionnaires comprise managers of the organizations who are responsible in making key decisions for the department concerned. Five main issues were addressed in the questionnaires toward effective implementation of teleworking, which includes but not limited to: organizational values, advantages of teleworking, performance evaluation, strategical measures and information technology requirements. A total number of 600 questionnaires for each of Group I and Group II were distributed to 
various business organizations such as banking (13), insurance (12), financial (44), service (189), legal firm (46), software industries (46), telecommunication (8), real estate (39), travel agent (46), architectural (46), management consultant (46) and others (65). Figure 1 represents this trend. The samples were selected randomly from the business organizations database. The selection of sample from various business organizations was based on the employment of a large workforce performing data entry, word processing and other informationoriented jobs (Katz, 1987).

The characteristics of teleworking jobs are: 1) minimal physical facility requirements; 2) little face-to-face interaction with other people; 3) concentration and large blocks of time when employees work independently; 4) projects can be completed with medium term deadlines; 5) jobs can be performed without close supervision. A high proportion of employees was involved in information-oriented, in other words, teleworking jobs in the selected organizations. The selected organizations were small, medium and large-scale categories both in terms of number of employees and business turnover. A reply paid self-addressed envelope was attached with each of the questionnaire and distributed to the selected business organizations by using postal mail method allowing a response period of about two to three weeks. However, it has taken nearly a month for the respondents to return the completed questionnaire. The response rate for Group I and Group II were 1.7\% (10) and $11 \%$ (66) respectively. This paper highlights only the findings of group II questionnaire because of very low response rate from Group I.

It is noted that the decision to implement telework by the managers is very much essential for an increased growth of teleworking. The decision to consider teleworking is greatly influenced by many factors. Five main factors were identified to model the decision to implement teleworking. Figure 2 represents the decision process to implement teleworking. The attitudes of the managers were carefully studied for the presence of positive or negative responses on each of the identified factors. A binary logistic regression model was developed to test the significant effect of each of these factors against the decision to implement teleworking. 


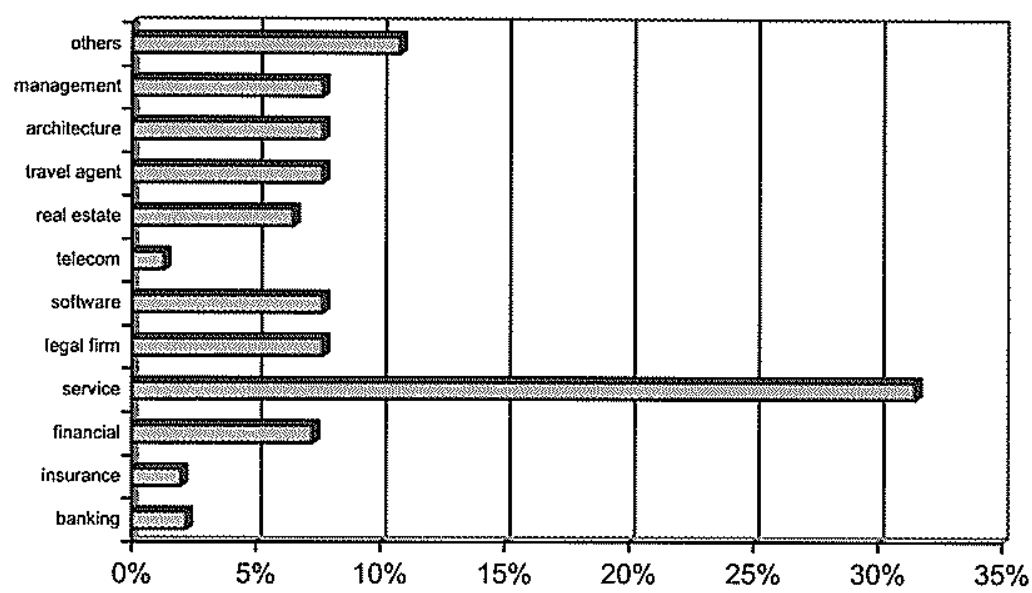

Figure 1: Distribution of sample by business category

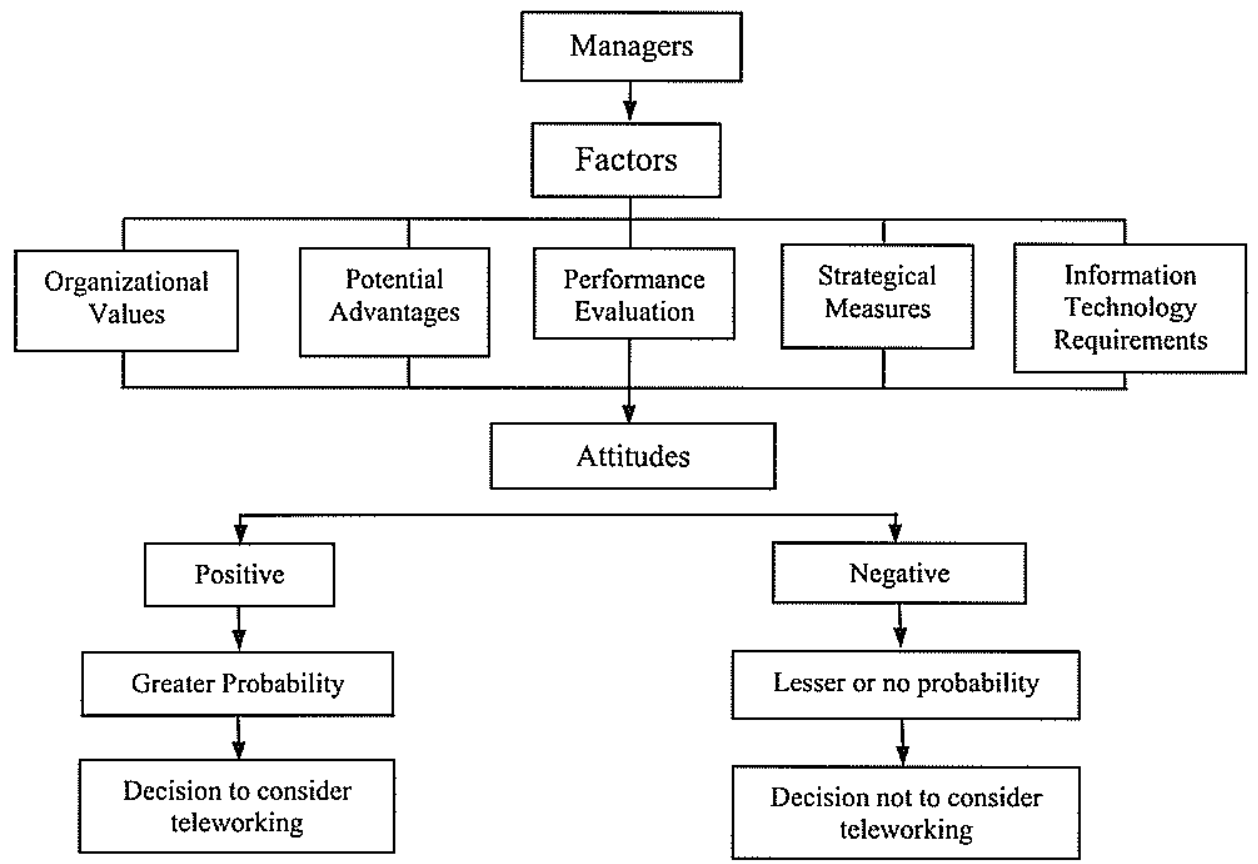

Figure 2: A simple flow chart representing the decision to implement teleworking 
Many researchers pointed out the lack of adoption of teleworking due to management's resistance to the lack of visibility and control that telework entails (Cross \& Raizman, 1986, Gordon \& Kelly, 1986). Managers who have closely supervised their employee's work or who have relied on visual cues to assess performance might find it difficult or time-consuming to shift to a "manage by results" paradigm. The resistance to change by traditional managers can be traced to a long history of organizational discourse revolving around bureaucratization, mass production and stability (Orlikowski, 1996). Traditional office environment is a legacy of industrialization and factory system and that telework might not be adopted because it threatens organizational and personal norms, separation of home and work activities (Kraut, 1987). The basis for the resistance to telework is also found in the technological structure of organizations. Technological innovations and organizational form are recursively linked, and acceptance of telework is associated with changes in both areas (Ellison, 1999). The discussion on the concept of trust that teleworkers are truly working had appeared in many literatures that deal with teleworking. As one author wrote, "How do you manage people who you do not see? The simple answer is, by trusting them, but the apparent simplicity disguises a turnaround in organizational thinking" (Handy, 1995). Olson observes that managers felt that supervising teleworkers entailed more work for them and they did not feel this additional time was particularly beneficial, even if it resulted in better planning and time estimates (Olson, 1989).

A consistent theme throughout the literature reveals that isolation, one of the disadvantages of teleworking, is a key factor limiting the adoption of teleworking (Forester, 1989, Pratt, 1984). Stohl argues that people are less identified with the organizations, and co-workers are not available for social and task support when employees are not co-located (Stohl, 1995). Olson has explicated the importance of organizational culture in determining the adoption of telework which indicates organizations typically express and reflect organizational norms through the physical location of the organization. Managerial resistance to telework may result in various forms of subtle sabotage such as increased on-site meetings (Olson, 1988) and the demand for more deliverables (Perin, 1991).

The managerial resistance to telework is clearly seen as impedance in promoting the growth of teleworking in Japan. The decision to practice teleworking by the managers of the organizations is obviously seen in terms of organizational value, potential advantages of teleworking, performance evaluation, strategical measures and information and communication technology from the literature on teleworking research. These five measures are adopted in the questionnaire survey in ascertaining the perceptions of managers 
in different organizations in Japan toward teleworking. Each of these measures is further categorized into suitable classes of responses. To exemplify, culture, traditional work style, identity of the organization, and competitiveness were used as the yardstick to measure organizational values. Similarly, performance evaluation is categorized into interaction between management and employees, additional responsibilities for the management, trust, training, and performance of employees. It is highly seen that positive perceptions toward these measures would attribute to a greater acceptance of teleworking as a formal work arrangement by the managers of the organizations. Otherwise, it would reduce the growth of teleworking.

\section{Development of a model}

Prior to developing a model, each of the identified factors such as organizational value, advantages of teleworking, performance evaluation, strategic measures and information technology requirement against decision to implement teleworking was tested for statistical significance both at $95 \%$ and $99 \%$ confidence interval by using Chi-square method. It was estimated that all the factors were found to be statistically significant both at $95 \%$ and $99 \%$ confidence interval. This test, however, accounts only for the effect of each of the factors separately against decision to implement teleworking. Having this in mind, it necessitates to test combined effect of each of the factors against decision to implement teleworking for a better understanding which was eventually carried out by developing a logistic regression model.

A binary logistic regression model was developed to estimate logistic regression coefficient for the estimation of odd ratios for each of the independent variables in the model. The dependent variable is a dichotomous in nature, which was categorized as 1 for managers who are willing to introduce teleworking and 0 for not willing to introduce teleworking. The probability of an event occurring, as given by logistic regression model, is structured as in equation 1 (Marija J. Norusis, 1999):

Prob $($ event $)=1 /\left(1+\mathrm{e}^{-\mathrm{z}}\right)$

where $\mathrm{z}$ is the linear combination and

$e$ is the base of natural logarithms 
$z=B_{0}+B_{1} X_{1}+B_{2} X_{2}+\ldots .+B_{p} X_{p}$

$\mathrm{B}_{0}=$ constant

$\mathrm{B}_{1}, \mathrm{~B}_{2}, \mathrm{~B}_{\mathrm{p}}=$ parameter coefficient

$\mathrm{X}_{1}, \mathrm{X}_{2}, \mathrm{X}_{\mathrm{p}}=$ independent variables

$\mathrm{p}=$ number of independent variables

The estimation of resulting value from the equation 1 is a probability value that varies between 0 and 1 . A value close to zero means that the event is very unlikely to have occurred and a value close to 1 means that the event is certain to have occurred. It is noted that each predictor variable in the equation 2 has its own coefficient. These parameters are estimated by fitting models, based on the available predictors, to the observed data. The chosen model will be the one that, when values of the predictor variables are placed in it, results in values of an event closest to the observed outcomes. Specifically, the values of the parameters of the model are estimated using the maximum-likelihood method, which selects coefficients that make the observed outcomes most likely to have occurred (Field A, 2000). Since the logistic regression model is nonlinear, an iterative algorithm was used for parameter estimation.

\section{DECISION TOWARD IMPLEMENTING TELEWORKING}

The managers' decision whether or not to implement teleworking is considered vital for an upsurge in the growth of teleworking. In the present work environment, many managers were found to be largely skeptical toward teleworking due to various obvious reasons. This section examines this trend accompanied by general observation and personal characteristics of the sample.

\section{General Observation of the sample}

The respondents were found to be predominately male managers as compared to female counterparts. Nearly $86.5 \%$ were found to be male managers whereas only $9 \%$ constitute female managers. It clearly showed greater gender differences in the top management positions, as it has been very much a realistic phenomenon both in the past and present Japanese corporate world. Not surprisingly, older male managers, as it is seen as a general norm in the Japanese business community, were found to be occupied the executive 
positions of the organizations. About $29 \%$ of the managers were found to be in the age group of 51-60 years followed by $23 \%$ between $41-50$ years, $20 \% 31-40$ years, $13.5 \% 20-30$ years and $10.5 \%$ more than 60 years. The number of years in the decision making position of the managers had revealed that nearly $41 \%$ of the respondents were belong to more than 10 years category followed by $24 \%$ less than 2 years, $17 \%$ between 5 and 10 years and $14 \%$ between 2 and 5 years category.

\section{Personal characteristics}

Overall, the analysis of the sample has revealed relatively a fewer number of female managers in different business organizations. The decision against to introduce telework was found to be high among male managers as compared to female counterparts. About $73 \%$ of male manager were against the practice of teleworking, compared to $67 \%$ of female counterparts. The other interesting finding of the sample was that both the middle and older aged managers were found to be more optimistic toward teleworking as compared to younger counterparts. Nearly $43 \%$ of managers older than 60 years were positive about introducing teleworking compared to $32 \%$ of managers $51-60$ years old and $33 \%$ of managers $41-50$ years. On the other hand, about $92 \%$ of those in the age group 31-40 years were against introducing teleworking followed by $78 \%$ of those 20-30 years old. Surprisingly, managers with more experiences were found to be more optimistic toward teleworking as compared to less experienced counterparts. About $41 \%$ of those belong to more than 10 years of experience in the manager category were expressed optimistic toward teleworking as compared to only $19 \%$ in the $<2$ years category.

\section{Organizational value}

Generally speaking, the analysis has shown a high percentage of disagreement toward implementing teleworking by the managers. Nearly $70 \%$ of the respondents were found to be against the practice of introducing teleworking as compared to only about $27 \%$ who were expressed optimistic toward teleworking. The various issues responsible for the greater percentage of disagreement toward teleworking encompass: nearly $59 \%$ of the managers who were against the practice of teleworking $(n=46)$ were reportedly agreed that the practice of teleworking would jeopardize organizational value and thus considered one of the main obstacles toward implementing teleworking.

About $41 \%$ of these respondents $(n=28)$ were agreed that teleworking would decreases organizational culture (as against about $45 \%$ who disagreed), $59 \%$ agreed it eradicates traditional work style (as against $28 \%$ who disagreed), 
which clearly shows how imperative it is to the company, $48 \%$ agreed it would ultimately loses organizational identity (as against $35 \%$ who disagreed), $35 \%$ agreed it declines considerably organizational competitiveness (as against $48 \%$ who disagreed), and $31 \%$ agreed it would addresses weakness of the organization (as against $48 \%$ who disagreed). Figure 3 illustrates this trend. On the other hand, about $33 \%$ of the managers who were against the practice of teleworking were reportedly agreed that organizational value does not constitute as a main hindrance for their reluctance to consider teleworking.

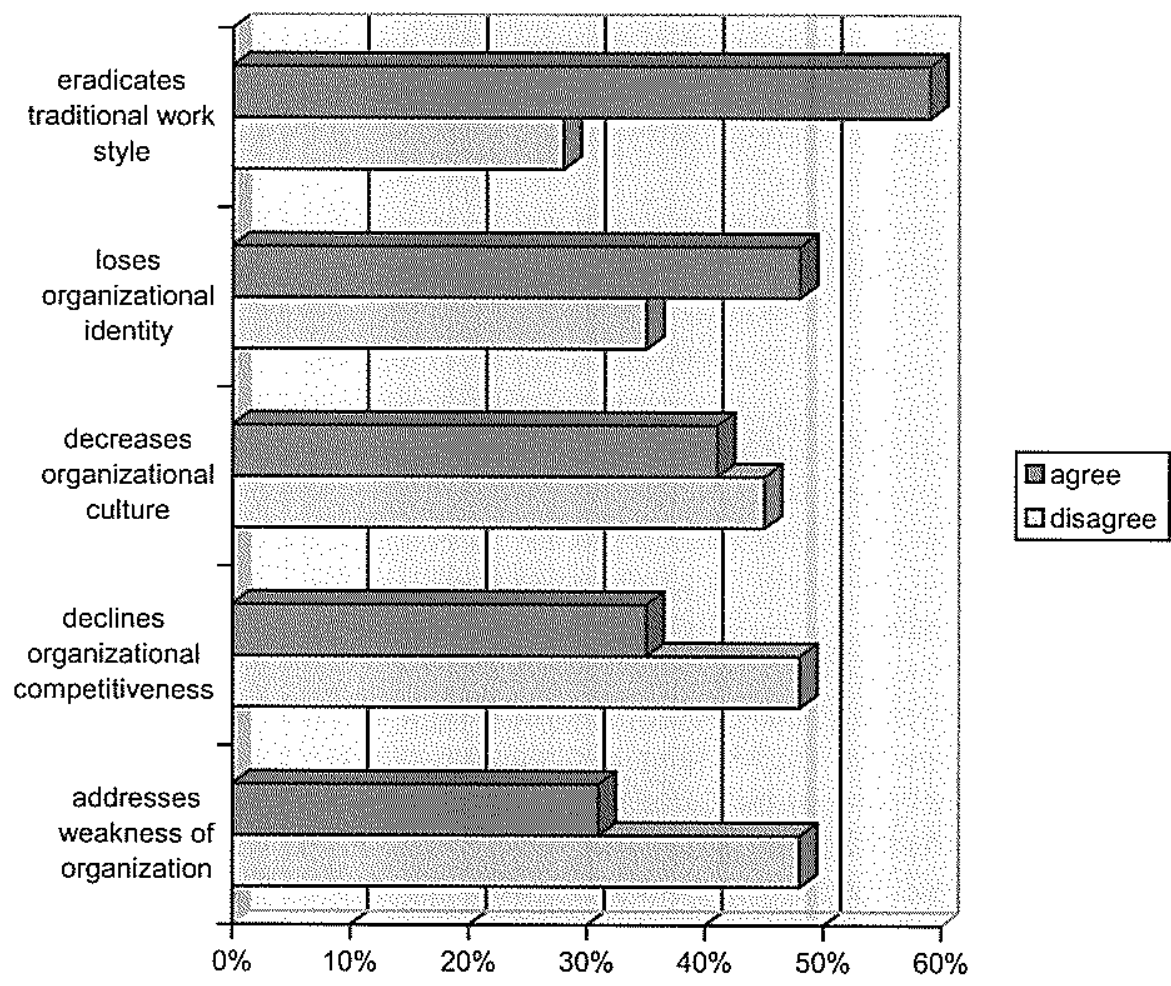

Figure 3: Pessimistic managers' perceptions of organizational value 


\section{Disadvantages of teleworking}

The findings also showed that disadvantages of teleworking were one of the primary issues for the respondents who expressed pessimism toward teleworking. Nearly $65 \%$ of the respondents $(n=46)$ were expressed disadvantages of teleworking was one of the main issues for their reluctance to consider teleworking for their organizations.

About $47 \%$ of these respondents $(n=30)$ agreed that the practice of teleworking would necessitate expensive initial investment (as against $44 \%$ who disagreed), $44 \%$ agreed that teleworking would jeopardizes public relations with the company (as against 31\% who disagreed), 69\% agreed that the practice of teleworking would eventually creates security concern over the official confidential documents (as against $22 \%$ who disagreed), which is widely considered very much imperative for many organizations, and surprisingly only $34 \%$ agreed that isolation would result in a less competent worker over time as a result of practicing teleworking (as against $44 \%$ who disagreed). This is depicted in figure 4 . Meanwhile, only $20 \%$ of the respondents who were found to be pessimistic about teleworking were reportedly admitted that disadvantages of teleworking does not necessarily constitute as a main reason for their reluctance to consider for their potential employees.

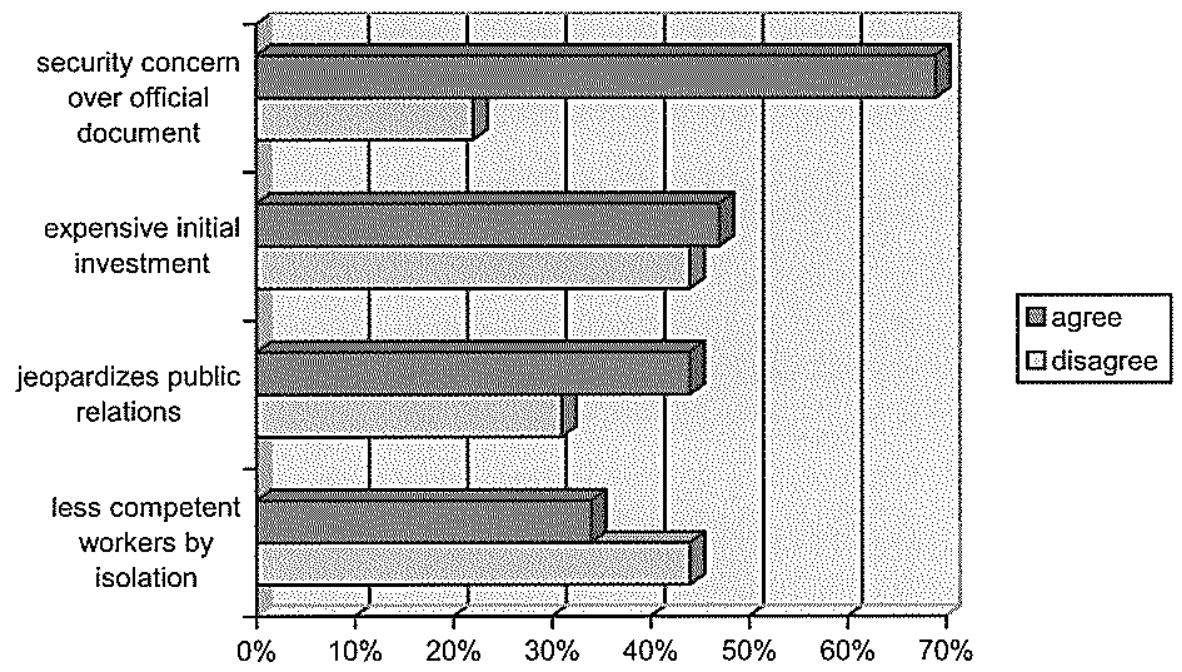

Figure 4: Pessimistic managers' perceptions of disadvantages of teleworking 


\section{Performance evaluation}

The evaluation of the performance of the teleworkers has been rather reported to be a difficult task, as claimed by many supervisors, especially due to physical absence of the workers at the main central workplace. The perception of the respondents on this issue toward teleworking was recorded. Nearly $61 \%$ of the managers who were against the practice of teleworking $(\mathrm{N}=46)$ were agreed that performance evaluation of remote workers is one of main hindrances for their reluctance to introduce teleworking.

A relatively high number of respondents $(84 \%)(n=28)$ agreed that teleworking would eventually decreases interaction between managers and employees (as against $13 \%$ who disagreed) as a result of practicing teleworking. Nearly $87 \%$ of the respondents agreed that the practice of teleworking would postulates additional responsibilities for the managers (as against 10\% who disagreed), which is viewed widely as one of the main cause for pessimism toward teleworking especially in Japan, $48 \%$ agreed that physical absence from the central workplace would casts doubts on the employees whether or not he/she is truly performing his/her job (as against $32 \%$ who disagreed), $71 \%$ agreed that adequate training is very much needed to educate employees on the technicality of teleworking (as against $26 \%$ who disagreed) if employees are allowed to telework, and only $26 \%$ of the respondents agreed that teleworking would ultimately decreases performance of employees over a long period (as against $45 \%$ who disagreed). This is shown graphically in figure 5 . On the other hand, about $22 \%$ of the respondents were unconvinced that performance evaluation of teleworkers was a major hindrance for their unwillingness to introduce teleworking.

\section{Non-strategical Measures}

On the issue whether or not teleworking is a strategical measures in improving the overall performance of the organizations, about $57 \%$ of the managers who were against introducing teleworking $(n=46)$ agreed that teleworking is being considered as a non-strategical measures in improving overall performance of the organizations.

Nearly $54 \%$ of these respondents $(n=27)$ agreed that teleworking would not help to achieve an overall improvement for the organization (as against $25 \%$ who disagreed), a relatively high percentage, about $93 \%$, disagreed that the practice of teleworking would eventually lead to weaken company status, only $4 \%$ agreed that it helps to decrease the number of skilled workforce for the company (as against $93 \%$ who disagreed), $32 \%$ agreed that teleworking would eventually reduces a balanced workforce, otherwise sustained, for the company 
(as against $57 \%$ who disagreed) if teleworking is being introduced for the potential employees of the organizations. Figure 6 shows this trend. On the contrast, only $28 \%$ of the respondents were completely disagreed that teleworking as a non-strategical measure in ameliorating the overall performance of the organizations.

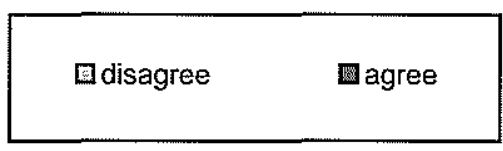

additional resp. for managers decrease interaction between emp'r \& emp'e adequate training is needed casts doubts whether emp'e working decreases performance of employees

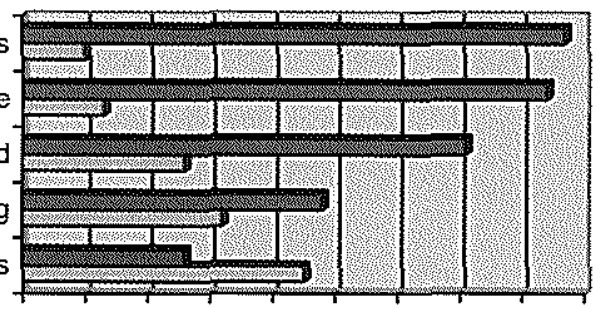

$0 \% 10 \% 20 \% 30 \% 40 \% 50 \% 60 \% 70 \% 80 \% 90 \%$

Figure 5: Pessimistic managers' perceptions of performance evaluation

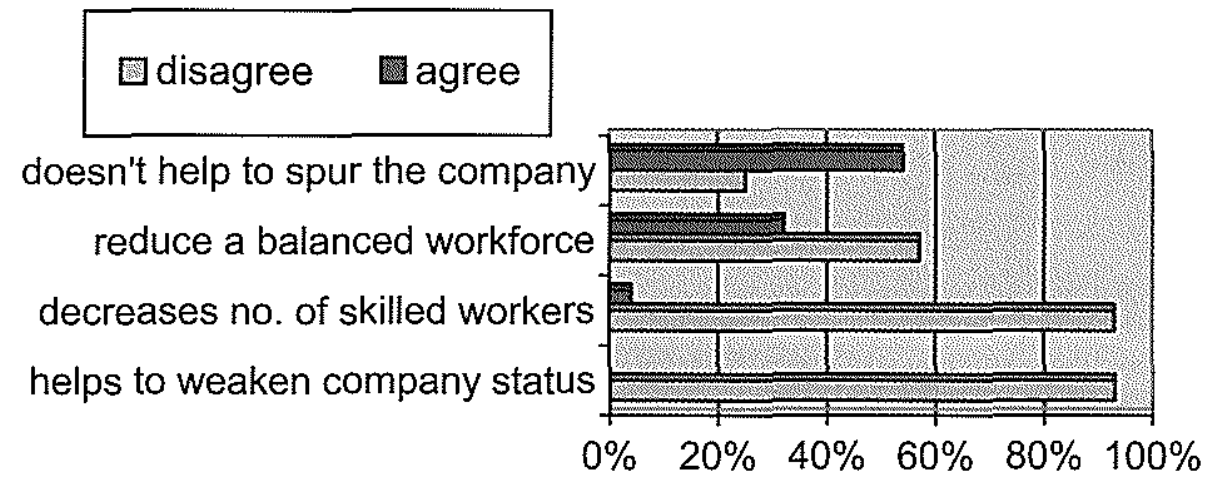

Figure 6: Pessimistic managers' perceptions of non-strategical measures 


\section{Lack of progress in Information Technology}

Finally, the perception on whether or not lack of progress in the information technology was the main obstacle in introducing teleworking was recorded. It had revealed that only $33 \%$ of the respondents $(n=46)$ were reported to be positive that the lack of progress in the information technology was a main factor for their high pessimism toward teleworking.

Nearly $60 \%$ of these respondents $(n=15)$ agreed that the cost involved in setting up information technology hardware either for a home-based or centre-based office is very high (as against $40 \%$ who disagreed), about $47 \%$ agreed that importance of information technology is not well understood (as against the same percentage of the respondents, $47 \%$, who disagreed), nearly $53 \%$ agreed that the skills acquired to use information technology hardware by the employees is very low level (as against $33 \%$ who disagreed), about $73 \%$ of the respondents agreed security concern as a result of transferring documents online was not increased considerably (as against $27 \%$ who disagreed), and lastly $67 \%$ agreed that both quality and quantity of online documentation was very poor (as against $27 \%$ who disagreed) for their reluctance to introduce teleworking. This is clearly depicted in figure 7 . Meanwhile, about $52 \%$ of the respondents have failed to agree that the lack of progress in the information and communication technology was the main reason for their pessimism toward teleworking.

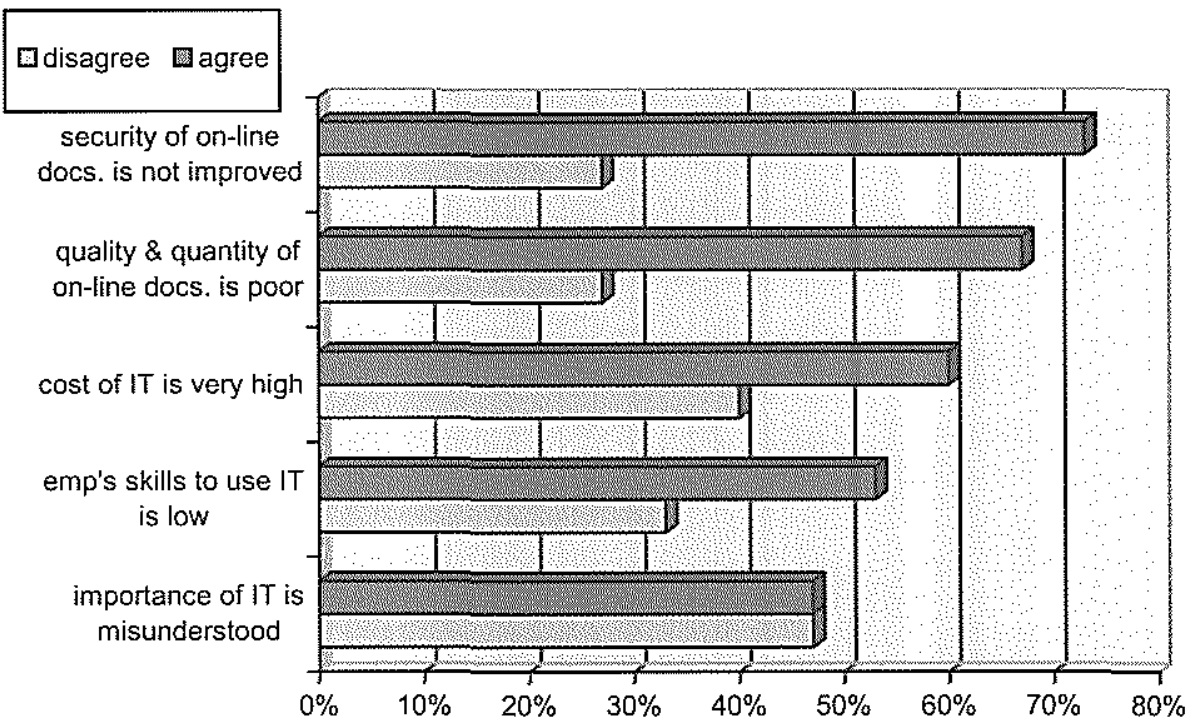

Figure 7: Pessimistic managers' perceptions of lack of progress of IT 
Table 1: Pessimistic managers' perceptions of teleworking issues

\begin{tabular}{|c|c|c|c|c|}
\hline Factor & " Statement & Agree & Disagree & $\begin{array}{c}\text { Sample } \\
\text { size }\end{array}$ \\
\hline $\begin{array}{l}\text { Organizational } \\
\text { value obstacle } \\
\text { vs. introduce } \\
\text { teleworking }\end{array}$ & $\begin{array}{l}\text { a. decreases organizational } \\
\text { culture } \\
\text { b. eradicates traditional work } \\
\text { style } \\
\text { c. loses organizational identity } \\
\text { d. declines organizational } \\
\text { competitiveness } \\
\text { e. addresses weakness of } \\
\text { organization } \\
\end{array}$ & $\begin{array}{l}41 \% \\
59 \% \\
48 \% \\
35 \% \\
31 \%\end{array}$ & $\begin{array}{l}45 \% \\
28 \% \\
35 \% \\
48 \% \\
48 \%\end{array}$ & 28 \\
\hline $\begin{array}{l}\text { Disadvantages } \\
\text { vs. introduce } \\
\text { teleworking }\end{array}$ & $\begin{array}{l}\text { a. expensive initial investment } \\
\text { b. jeopardizes public relations } \\
\text { c. security concern over official } \\
\text { document } \\
\text { d. Less competent worker by } \\
\text { isolation }\end{array}$ & $\begin{array}{l}47 \% \\
44 \% \\
69 \% \\
\\
34 \%\end{array}$ & $\begin{array}{l}44 \% \\
31 \% \\
22 \% \\
44 \%\end{array}$ & 30 \\
\hline $\begin{array}{l}\text { Performance } \\
\text { evaluation } \\
\text { hindrance vs. } \\
\text { introduce } \\
\text { teleworking }\end{array}$ & $\begin{array}{l}\text { a. decrease interaction bet. emp'r } \\
\text { \& emp'e } \\
\text { b. additional respn. for managers } \\
\text { c. casts doubts whether empls. } \\
\text { working } \\
\text { d. adequate training is needed } \\
\text { e. decreases performance of } \\
\text { employees }\end{array}$ & $\begin{array}{l}84 \% \\
87 \% \\
48 \% \\
71 \% \\
26 \%\end{array}$ & $\begin{array}{l}13 \% \\
10 \% \\
32 \% \\
26 \% \\
45 \%\end{array}$ & 28 \\
\hline $\begin{array}{l}\text { Non-strategical } \\
\text { measures vs. } \\
\text { introduce } \\
\text { teleworking }\end{array}$ & $\begin{array}{l}\text { a. doesn't help to spur the } \\
\text { company } \\
\text { b. helps to weaken company } \\
\text { status } \\
\text { c. decreases number of skilled } \\
\text { workers } \\
\text { d. reduce a balanced workforce }\end{array}$ & $\begin{array}{r}54 \% \\
\text { nil } \\
4 \% \\
32 \% \\
\end{array}$ & $\begin{array}{l}25 \% \\
93 \% \\
93 \% \\
57 \% \\
\end{array}$ & 27 \\
\hline $\begin{array}{l}\text { Lack of } \\
\text { progress in IT } \\
\text { vs. introduce } \\
\text { teleworking }\end{array}$ & $\begin{array}{l}\text { a. cost involved in IT is very } \\
\text { high } \\
\text { b. importance of IT is } \\
\text { misunderstood } \\
\text { c. employees skills to use IT is } \\
\text { low } \\
\text { d. security of online-docs. is not } \\
\text { improved } \\
\text { e. quality \& quantity of online- } \\
\text { docs. is poor }\end{array}$ & $\begin{array}{l}60 \% \\
47 \% \\
53 \% \\
73 \% \\
67 \% \\
\end{array}$ & $\begin{array}{l}40 \% \\
47 \% \\
33 \% \\
27 \% \\
27 \%\end{array}$ & 15 \\
\hline
\end{tabular}

(Source: Primary survey 2000) 


\section{Output of the model}

Overall, the decision to implement teleworking, as perceived by the managers, was largely found to be against the practice of teleworking. Only $27 \%$ of the respondents were found to be positive that teleworking would bring benefits to the organization as against $70 \%$ who were against the practice of teleworking. It is presumed that the negative perceptions toward teleworking is attributed to factors such as organizational value, disadvantages of teleworking, difficulty in evaluating the performance of teleworkers, teleworking considered as a nonstrategical measures and lack of progress in the information technology field. To determine the collective contribution of each of these factors against decision to telework, a binary logistic regression model is developed. The output of the model is shown in table 2.

The significance of each of the selected factors against the decision to implement teleworking was assessed based on the estimated coefficients of the independent variables. The results of the model have showed that the parameter coefficient for each of these factors against the decision to implement teleworking is negative except for the factor related to difficulties in evaluating the performance of teleworkers. The interpretation of the parameter coefficients in a logistic regression model is made in terms of log odds of an event occurring i.e., the ratio of the probability of an event occurring to the probability of an event not occurring. The parameter coefficient of the importance of organizational value as a major obstacle indicates that when this factor changes from not a major obstacle $(=0)$ to major obstacle $(=1)$ and other independent variables remain the same, the $\log$ odds of the decision to implement teleworking decreases by 2.485 . Similarly, the log odds of the decision to implement teleworking were found to be decreased by 2.561 when the value of the factor disadvantages of teleworking increases from 0 (not considered as disadvantages) to 1 (considered disadvantages). Considering teleworking as a strategical measures $(=0)$ to non-strategical measures $(=1)$ has resulted a decrease in the decision to implement teleworking by 1.220 . Finally, the decision to implement teleworking was estimated to be decreased by 1.141 when managers perception on the progress in the information technology changes from significant progress $(=0)$ to lack to progress $(=1)$. However, the estimation of Wald statistics has showed that only the coefficients for factors such as organizational value as a major obstacle and disadvantages of teleworking appear to be significantly different from 0 using a significance level of 0.05 . The ratio of the odds of implementing teleworking when organizational value is viewed as a major obstacle to the same odds when organizational value is not viewed as a major obstacle was estimated to be 0.083 . Similarly, the odds 
ratio of other factors is also given in table 2 . The $\mathrm{R}^{2}$ statistics indicates that this model only explains about $53 \%$ of the "variation" in the outcome variable.

Table 2: Output of the model

\begin{tabular}{|c|c|c|c|c|c|c|}
\hline \multirow[t]{2}{*}{ Variable } & \multirow[t]{2}{*}{$\begin{array}{l}\text { Parameter } \\
\text { coefficient }\end{array}$} & \multirow[t]{2}{*}{$\begin{array}{c}\text { Wald } \\
\text { statistics }\end{array}$} & \multirow[t]{2}{*}{ Significance } & \multirow[t]{2}{*}{$\operatorname{Exp}(B)$} & \multicolumn{2}{|c|}{$\begin{array}{c}95 \% \text { C.I. for } \\
\text { Exp(B) }\end{array}$} \\
\hline & & & & & Lower & Upper \\
\hline Constant & 0.934 & 3.117 & 0.075 & 2.545 & - & - \\
\hline $\begin{array}{l}\text { Importance of } \\
\text { organizational } \\
\text { value a major } \\
\text { obstacle }(1=\text { yes; } \\
0=\text { otherwise })\end{array}$ & -2.485 & 7.315 & 0.007 & 0.083 & 0.014 & 0.504 \\
\hline $\begin{array}{l}\text { Disadvantages of } \\
\text { teleworking }(1= \\
\text { yes; } 0= \\
\text { otherwise })\end{array}$ & -2.561 & 5.863 & 0.015 & 0.077 & 0.010 & 0.614 \\
\hline $\begin{array}{l}\text { Difficulties in } \\
\text { performance } \\
\text { evaluation of } \\
\text { teleworkers ( } 1= \\
\text { yes; } 0= \\
\text { otherwise) }\end{array}$ & 1.043 & 0.959 & 0.327 & 2.837 & 0.352 & 22.855 \\
\hline $\begin{array}{l}\text { Non-strategical } \\
\text { measures }(1= \\
\text { yes; } 0= \\
\text { otherwise) }\end{array}$ & -1.220 & 1.559 & 0.212 & 0.295 & 0.043 & 2.004 \\
\hline $\begin{array}{l}\text { Lack of progress } \\
\text { in IT }(1=\text { yes; } 0= \\
\text { otherwise })\end{array}$ & -1.141 & 1.071 & 0.301 & 0.319 & 0.037 & 2.775 \\
\hline \multicolumn{6}{|c|}{ Initial -2 Log Likelihood (-2LL) } & 76.049 \\
\hline \multicolumn{6}{|c|}{ Chi-square statistics } & 29.655 \\
\hline \multirow{2}{*}{\multicolumn{6}{|c|}{$\begin{array}{l}\text { Significance } \\
R \text { squre }\left(R^{2}\right)\end{array}$}} & 0.000 \\
\hline & & & & & & 0.533 \\
\hline
\end{tabular}

(Source: Primary survey)

\section{CONCLUSIONS}

It is largely seen that teleworking is still at a very slow pace of growth in the Japanese business establishments. The reluctance to accept teleworking as a formal work arrangement by the managers plays a central role toward this trend. This paper analyses the perceptions of the managers toward accepting teleworking for their compatible workforce. The findings clearly showed that 
the managers of the different business organizations were still found to be largely pessimistic for any plan related to the practice of teleworking. Nearly $70 \%$ of the managers were found to be largely pessimistic in incorporating teleworking as an alternate work arrangement for their potential employees. The unwillingness to compromise organizational value, perceived disadvantages of teleworking, difficulties in evaluating the performance of teleworkers, if allowed to telework, conceiving teleworking as a non-strategical measure or tool in improving business related activities, and finally lack of progress in the field of information and communication technology were found to be few reasons for their reluctance to consider teleworking as a formal work arrangement. Nearly $59 \%$ of the managers who were against the practice of teleworking were reportedly agreed that the practice of teleworking would jeopardize organizational value and thus considered one of the main obstacles toward implementing teleworking. On the disadvantages of teleworking, nearly $65 \%$ of the respondents expressed disadvantages of teleworking as one of the main issues for their reluctance to consider teleworking for their organizations. The findings also showed that about $61 \%$ of the managers who were against the practice of teleworking agreed that performance evaluation of remote workers is one of the main hindrances for their reluctance to introduce teleworking. About $57 \%$ of the managers who were against introducing teleworking agreed that teleworking is being considered as a non-strategical measure in improving overall performance of the organizations. Finally, nearly $33 \%$ of the respondents were reported to be positive that the lack of progress in the information technology was one of the main factors for their high pessimism toward teleworking. Even though, the generalization of this finding should be treated with extreme caution because of very low sample size, it has, perhaps, created a platform to comprehend factors, which would affect decision of the managers toward accepting teleworking.

\section{REFERENCES}

Adolph I. Katz. 1987. "The Management, Control and Evaluation of a Telecommuting Project: A Case Study", Information and Management 13, pp. 179-190.

Field, A. 2000. Discovering Statistics using SPSS for Windows, Sage publications Ltd.

EPA. 2000. The effect of information technology on productivity: in search of Japan's "New Economy", Economic Planning Agency (EPA), http://www.epa.go.jp/2000/f/1031f-seisakukoka4-e/main.html

MPT 2000. "Statistics of telecommunications, Ministry of Post and Telecommunication (MPT)", http://www.mpt.go.jp/ 
Christensen, K. 1990. "Remote control: How to make telecommuting payoff for your company", PC Computing, Vol. 3, No.2, pp. 90-94

Cross T.B. \& Raizman, M. 1986. Telecommuting: The future technology of work, Homewood, IL: Dow Jones Irwin.

Hobbs, D and Armstrong, J. 1998. "An experimental study of social and psychological aspects of teleworking", Industrial Management \& Data Systems, pp. 214-218, MCB University Press.

Forester, T. 1989. The myth of the electronic cottage, In T. Forester (Ed.), Computers in the human context, Cambridge, MIT Press, MA, pp. 213227.

Gillespie, A. Richardson, R. and Cornford, J. 1995. Review of telework in Britain: Implications for Public Policy, CURDS, University of Newcastle upon Tyne, February.

Gordon, G \& Kelly, M. 1986. Telecommuting: How to make it work for you and your company, Englewood Cliffs, NJ, Prentice Hall.

Haddon, L and Lewis, A. 1994. "The experience of teleworking: An Annotated Review", International Journal of Human Resource Management, Vol. 5, No. 1, pp. 193-223.

Handy, C. 1995. Trust and the virtual organization, Harvard Business Review, Vol. 73, No. 3, pp. 31-32.

Huws, U. Honey, S. Morris, S. 1996. Teleworking and Rural Development, Rural Research Report No. 27, The Rural Development Commission.

Kraut, R. 1987. Predicting the use of technology: The case of telework. In R. Kraut (Ed.), Technology and the transformation of white-collar work, Hillsdale, NJ, Lawrence Erlbaum.

Marija J. Norusis. 1999. SPSS Regression Models 10.0, a software manual, SPSS Inc.

Nicole B. Ellison. 1999. Social Impacts: New Perspectives on Telework, Social Science Computer Review, Vol. 17, No. 3, pp. 338-356.

Olson, M.H. 1989. Telework: Effects of changing work patterns in time and space. Chapter 10 in Information Society and Spatial Structure, ed. H. Ernste and C. Jaeger. London: Belhaven.

Olson, M.H. 1988. Corporate culture and the homeworker. In K. Christensen (Ed.), The new era of home-based work: Directions and policies, Boulder, Westview, CO, pp. 126-134.

Orlikowski, W. 1996. Improvising organizational transformation over time: A situated change perspective, Information Systems Research, Vol. 7, No. 1, pp. 63-92.

Mokhtarian P L. and Koji Sato. 1994. "A Comparison of the Policy, Social and Cultural Contexts for Telecommuting in Japan and the United States", Social Science Computer Review Vol.12, No. 4. 
Perin, C. 1991. The moral fabric of the office: Panopticon discourse and schedule flexibility, In P. Tolbert \& S. Barley (Eds.), Research in the Sociology of Organizations, Greenwich, CT, pp. 243-270.

Pratt, J. 1984. Home teleworking: A study of its pioneers, Technological Forecasting and Social Change, 25, pp. 1-14.

Stohl, C. 1995. Organizational communication: Connectedness in action, Thousand Oaks, Sage, CA.

Suomi, R. 1997. Management Values and Telework, Second International Workshop on Telework, Vol II, Work and Organizational Research Centre.

Wendy A. Spinks. 1991. Satellite and resort offices in Japan, Transportation, Vol. 18, pp. 343-363. 